This document is the accepted manuscript version of the following article:

Ahmadi, M., Farhadinia, M. S., Cushman, S. A., Hemami, M. R., Nezami Balouchi, B., Jowkar, H., \& Macdonald, D. W. (2020). Species and space: a combined gap analysis to guide management planning of conservation areas. Landscape Ecology, 35(7), 1505-1517. https://doi .org/10.1007/s10980-020-01033-5

Title:

\title{
2 SPECIES AND SPACE: a combined Gap analysis to guide management 3 planning of conservation areas
}

4

5 Authors:

6 3BD, UK Karaj, Iran 7

\section{Mohsen Ahmadi ${ }^{1,2 *}$, Mohammad S. Farhadinia ${ }^{3}$, Samuel A. Cushman ${ }^{4,5}$, Mahmoud-Reza Hemami $^{1}$, Bagher Nezami Balouchi ${ }^{6}$, Houman Jowkar ${ }^{7}$, David W. Macdonald ${ }^{4}$}

\section{Affiliations and addresses:}

${ }^{1}$ Department of Natural Resources, Isfahan University of Technology, 8415683111 Isfahan, Iran. ORCID: https://orcid.org/0000-0002-9657-699X

${ }^{2}$ Swiss Federal Research Institute WSL, Dynamic Macroecology Group, 8903 Birmensdorf, Switzerland

${ }^{3}$ Oxford Martin School and Department of Zoology, University of Oxford, 34 Broad Street, Oxford OX1

4 Wildlife Conservation Research Unit, Department of Zoology, University of Oxford, Tubney, Abingdon OX13 5QL, UK

${ }^{5}$ Rocky Mountain Research Station, United States Forest Service, Flagstaff, 86004 AZ, USA

${ }^{6}$ Department of Natural Resources and Environment Sciences, University of Environment, 3174674761

${ }^{7}$ Conservation of Asiatic Cheetah Project (CACP), I.R. Iran Department of Environment, 738314155

Teheran, Iran

\section{* Corresponding Authors:}

Mohsen Ahmadi, Department of Natural Resources, Isfahan University of Technology, 8415683111 Isfahan, Iran. Phone number: +989104897500, Email: ahmadim.bio@ gmail.com 


\section{Abstract}

30 Context With accelerating global declines in biodiversity, establishment and expansion of

31 conservation areas (CAs) have increasingly been advocated in recent decades. Gap analysis has

32 been useful to evaluate the sufficiency and performance of CAs.

33 Objectives Researchers often identify putative gaps in the protection of biodiversity in CA

34 networks, drawing on evidence from species occurrence patterns (i.e., representation), yet the

35 effect on the gap analyses of the spatial configuration of CAs is poorly understood.

Methods Focusing on two large, charismatic carnivores of western Asia, Persian leopard and

37 Asiatic cheetah, we used species distribution models (SDMs) to map potentially suitable habitats

38 throughout the region. We calculated species representation for four categories of CAs within the

39 conservation network in Iran and used a new application of graph theory to include their spatial

40 configuration into our gap analysis. We then regressed species representation against spatial

41 configuration to provide more insights into the performance of different categories of CAs.

42 Results Results showed that the existing CA network conserves only $32 \%$ of the suitable habitats

43 for the two species. Leveraging spatial configuration of the conservation areas into the gap

44 analysis, however, revealed that the recently-established less strictly CAs disproportionately

45 provide a higher contribution to the collective effectiveness of the entire conservation network.

46 Conclusions We introduce network bias as a new concept in reserve design and argue that

47 incorporating spatial configuration into CA gap analysis improves the ability to evaluate the

48 effectiveness of reserve network designs, and is an important decision support tool for integrated

49 conservation planning. 
50 Keywords: conservation network, species distribution models, graph theory, connectivity, large

51 carnivores, conservation planning.

\section{Introduction}

54 Conservation areas (CAs) are critical to sustaining natural ecosystems in the context of expanding

55 human impact. Although covering only 15\% of Earth's terrestrial area (Juffe-Bignoli et al. 2014;

56 Visconti et al. 2019), the global conservation network has been rapidly expanded in the last decade

57 (Watson et al. 2014). However, CA networks still show substantial gaps in coverage of global

58 biodiversity (Jenkins et al. 2013). Gap analysis and conservation prioritization have been

59 extensively applied to evaluate the sufficiency of existing conservation networks and inform

60 decisions regarding new CA designations (Rodrigues et al. 2004b; Santini et al. 2014). The

61 immediate goal of a gap analysis is to quantifiably assess representativeness (i.e.,

62 complementarity) of biodiversity within CAs (Rodrigues et al. 2004b). While in many cases gap

63 analysis is used to compare across different taxa (Jenkins et al. 2013; Rodrigues et al. 2004b), in

64 others it is used to evaluate protection efforts (Araújo et al. 2007; Rodrigues et al. 2004a).

Among the 20 Aichi targets which the global community committed to in the Convention on

66 Biological Diversity (CBD), target 11 emphasizes expanding the current CAs to cover $17 \%$ of

67 terrestrial ecosystems by 2020, while preserving and improving network connectivity (CBD 2010).

68 Since then a multitude of literature has informed the ongoing expansion of CA network (Jenkins

69 et al. 2013), while many aspects of their functionality remain disregarded (Santini et al. 2014). For

70 example, the spatial configuration of core habitats (or CAs as the remaining strongholds) plays a

71 key role in the persistence of a species, particularly for large carnivores (Cushman et al. 2018; 
72 Macdonald et al. 2018). However, in many cases CAs are fragmented into small and isolated

73 patches, which may reduce performance in securing population viability (Santini et al. 2014),

74 Rapid ongoing human land-use changes further compound this by increasing degradation of

75 habitats outside of CAs and increasing the isolation of CAs from each other (Cushman et al. 2017;

76 Hearn et al. 2018; Macdonald et al. 2018). Moreover, location bias is a common type of

77 conservation inefficiency through which the establishment of CAs is concentrated in

78 topographically rugged landscapes, often at high elevations, away from human-dominated areas

79 (Gaston et al. 2008; Watson et al. 2014). Those 'rock and ice' areas (Joppa and Pfaff 2009), which

80 often have relatively low productivity and low species richness, appear to be established to

81 minimize conflicts with human land uses, and thus, bias towards these infertile or remote areas

82 has lessened conservation effectiveness (Venter et al. 2018).

Gap analysis has primarily been investigated in terms of species representation in CAs, which

84 in turn, is surrogated by habitat suitability maps (Maiorano et al. 2006; Yousefi et al. 2015) or 85 coarse-scale geographic ranges (e.g., extent of occurrence) and atlases (Araújo et al. 2007; Jenkins

86 et al. 2015). Species distribution models (SDMs) have been an operative tool to explore the 87 patterns of species distribution (Franklin 2010), with many applications to biodiversity 88 conservation (see Guisan et al. 2013 for a review). SDMs, by providing spatially explicit 89 predictions over unsampled areas, are particularly insightful for understanding large carnivores' 90 distribution dynamics and habitat mapping, and thus have been widely used to evaluate large 91 carnivores' habitat suitability (Ahmadi et al. 2017; Ashrafzadeh et al. 2018; Farhadinia et al. 2015).

92 Traditional gap analysis based on species representation usually focuses on how well CA 93 networks overlap, or "cover" the species distributions (Jennings 2000). Landscape ecology, and 94 the various metrics developed in it, have been frequently used to assess the spatial configuration 
95 of CAs (Cushman et al. 2018; Meyer et al. 2015) and their connectivity (Saura et al. 2018), yet

96 their appropriateness to gap analysis has not been critically evaluated (but see Santini et al. 2016).

97 In the current study, we based our gap analysis on the concept of focal species (Carroll et al. 2001)

98 to evaluate the effectiveness of, and quantify gaps in, Iran's conservation network. We focused on

99 the distribution of Persian leopard (Panthera pardus saxicolor, Pocock 1927) and Asiatic cheetah

100 (Acinonyx jubatus venaticus, Griffith 1821) in Iran, two conservation-dependent species with 101 different habitat requirements.

These two charismatic big cats are the paramount representatives of remaining terrestrial 103 habitats in western Asia (Farhadinia et al. 2017; Kiabi et al. 2002) and have been recognized as 104 landscape species in central Iranian plateau (Khosravi and Hemami 2019). Occurring in scattered 105 patches within semi-arid lowland areas of central and eastern Iran, a few dozen Critically 106 Endangered Asiatic cheetahs represent the last remnants of a historical population that spanned 107 western Asia (Farhadinia et al. 2017). In contrast, the Endangered Persian leopards inhabit rugged 108 terrain across much of western Asia and the Caucasus (Gavashelishvili and Lukarevskiy 2008). In 109 some arid regions of Central Iran, their distributions overlap (Hemami et al. 2018).

Here, we used SDMs to identify potentially suitable habitats for Persian leopard and Asiatic 111 cheetah in Iran and assessed the species representation in the CA network by calculating the 112 coverage of suitable habitats within Iran's CAs. We then used landscape connectivity metrics and 113 leveraged the spatial configuration of CAs into our gap analysis. Our combined approach for gap 114 analysis enabled us to evaluate the efficiency of different categories of CAs, given their 115 conservation strictness, species representation and spatial configuration for safeguarding these two 116 large carnivore species. This approach is potentially applicable in other species recovery planning 117 through enhancing gap analysis efforts. 


\section{Methods}

\section{Study Area and Species Data}

We confined the study to areas with the highest probability of occurrence of Persian leopard and Asiatic cheetah in Iran, covering a total area of 1.648 million $\mathrm{km}^{2}$ of the Iranian plateau (Fig. 1). This region of western Asia is an inland great basin which is bounded by a complex of mountain chains, including the Alborz and Zagros in the north and west, and the massifs of Afghanistan and Baluchistan in the east. Natural vegetation cover of the study area is characterized by (1) Hyrcanian forests, which form an arc from the Caspian Sea and the Alborz Mountains in the North, (2) patchy forest stands and shrublands distributed across rough steppes of the Zagros Mountains in the west, and (3) flat drylands with sporadic mountainous areas covered by xerophytic taxa of Artemisia siberi, Stipa sp. and Salsola sp. in the center of the plateau.

Generally, four categories of CAs are designated in Iran: National Parks (NPs), National Heritage Sites (NHSs) often called National Natural Monuments, Wildlife Refuge (WRs), and Protected Area (PAs). NPs are designated to protect outstanding environmental features and high biodiversity. Accordingly, the highest protection status is afforded to these areas. WRs and PAs are established and managed because of the high diversity of species in need of protection, and thus, WRs and PAs are in the next rank of conservation attention, respectively. These areas typically experience a higher intensity of human impacts due to the lower level of protection compared to NPs (Kolahi et al. 2012). In addition to these categories, No-Hunting Areas (NHA) are the least strictly protected category of Iranian conservation areas, where the main objective is

to empower anti-poaching measures. CAs of Iran correspond with Category II, Category III, Category IV and Category IV-VI of the IUCN. 
Species occurrence data were collected from direct field sampling by the authors (MSF, $142 \mathrm{BNB}$, and $\mathrm{HJ}$ ) and game rangers of the Department of Environment (DoE), and also from camera143 trap photographs obtained during 2010 - 2017. Altogether, 632 and 680 occurrence points were 144 compiled for Persian leopard and Asiatic cheetah, respectively (Table 1), covering the full 145 distribution of the species in Iran. Often, available data of the species' locations are spatially biased

146 toward areas easily assessed and/or better surveyed. In this situation, spatial autocorrelation among 147 locations can result in biased parameter estimates and over-representation of some regions 148 (Dormann et al. 2007). We ran a Global Moran's I test to assess the spatial autocorrelation of the 149 occurrence points across the study area. To address auto-correlation arising from the spatial150 dependency of the clumping points, we followed a spatial filtering procedure (Kramer-Schadt et 151 al. 2013) in which multiple points within a 5-km distance (Farhadinia et al. 2015) were removed. 152 After this spatial filtering 423 and 205 occurrence points of the two species were retained for SDM 153 modelling. For both species, presence locations were obtained through a long-term and continuous 154 monitoring program in all potential habitats. Therefore we are confident that our dataset doesn't 155 suffer significant sampling bias and incompleteness.

\section{Explanatory variables}

157 Four categories of environmental factors including land cover, prey availability, anthropogenic 158 and topographic variables were used in SDM. Land cover variables, including dense to moderate 159 density forest, scrub-shrub land, sparse vegetation, unvegetated bare lands (e.g. playas and salt 160 lands) and cropland, were extracted from a land cover map of Iran produced by Iranian Forests, 161 Ranges and Watershed Management Organization (IFRWO, 2010). A moving window procedure 162 was used to calculate the proportion of each cover type within a $5 \times 5 \mathrm{~km}$ grid. 
Small to medium-sized ungulates, including roe deer (Capreolus capreolus, Linnaeus 1758), 164 red deer (Cervus elaphus, Linnaeus 1758), bezoar goat (Capra aegagrus, Erxleben 1777), wild 165 sheep (Ovis orientalis, Linnaeus 1758), goitered gazelle (Gazella subgutturosa, Güldenstädt 1780) 166 and chinkara (G. bennettii, Sykes 1831), are the main prey of Persian leopard and Asiatic cheetah 167 in Iran (Farhadinia and Hemami 2010; Farhadinia et al. 2018a). Prey distribution data were 168 obtained from Karami et al. (2012). We overlaid shapefiles of the distribution of these prey species 169 and calculated distance to areas known to support them to obtain a composite map of their 170 distribution in Iran.

To include the anthropogenic effects in the species distribution models, we used the human

172 footprint model (Sanderson et al. 2002) which combines data on population density and the 173 presence of human infrastructure (i.e., road networks, land transformation, and human access). We 174 used the Shuttle Radar Topography Mission (SRTM) elevation model (http://srtm.csi.cgiar.org) to 175 measure elevation and topographic roughness (i.e., the standard deviation of the elevation of all 176 raster cells within a grid of $5 \times 5 \mathrm{~km}$ ). All the explanatory variables were resampled to a cell size 177 of $1 \times 1 \mathrm{~km}$ and projected to a Lambert conformal conic projection. Pairwise Pearson correlation 178 analysis was used to evaluate multi-collinearity among predictors, revealing no evidence of high 179 multi-collinearity (pairwise correlation coefficient for all predictors $<0.7$ ).

\section{$180 \quad$ Species distribution modelling}

181 To develop distribution models, we used two regression-based models including generalized linear 182 models (GLM) and generalized additive models (GAM), together with two high-performing 183 machine learning methods, generalized boosted models (GBM) and maximum entropy modeling 184 (MaxEnt). We then combined the resulting models into an ensemble model using the biomod2 185 package (Thuiller et al. 2009) in R 3.5 (R Development Core Team 2016). As all these models 
186 require background data (e.g., pseudo-absence points), we generated 10,000 background points

187 randomly distributed across the extent of the study area, excepting cells with presence points. We

188 used $75 \%$ of occurrence points for training the models and the remaining $25 \%$ was used to test

189 their performance. The area under the curve (AUC) of the receiver operating characteristic (ROC)

190 plot was used to assess discrimination capacity and the true statistic skill (TSS) was used to

191 evaluate the classification accuracy of models. We then converted the continuous ensemble model

192 for each species to binary presence/absence map considering 10th percentile of suitability score at

193 the occurrence points of each species as the classification threshold. Using this threshold has two

194 advantages. First, it allowed us to exclude marginal points that occurred in areas with very low or

195 none-suitable habitat conditions, and second, it enabled us to take into account the probable spatial

196 bias or uncertainties caused by outlier occurrence points.

The reliability of gap analysis depends on how accurately habitat patches are recognized and

198 incorporated into the procedure. To identify habitat patches we leveraged two preliminary rules

199 based on previous findings on the spatial ecology of the species. First, we retained habitat patches

200 larger than the minimum patch size needed to hold breeding populations of leopards in Iran, $\sim 250$

$201 \mathrm{~km}^{2}$, (Ghoddousi et al. 2010). We then calculated the nearest-neighbor distance between patches

202 and removed unoccupied habitat patches that were greater than $200 \mathrm{~km}$ from occupied patches [

203 equal to the longest movement has been recorded for Asiatic cheetah in arid ecosystems of Iran

204 (Farhadinia et al. 2016)] to exclude suitable patches from inaccessible areas.

\section{Gap analysis and conservation prioritization}

206 We based the gap analysis framework upon two methods, the degree of protection granted to the 207 suitable landscapes by the CAs, and ranking them using the probability of connectivity (PC) index.

208 For the degree of protection granted by each conservation category, we calculated total 
conservation coverage (i.e., the proportion of conserved areas from the total suitable habitats), and conservation efficiency (i.e., the proportion of conserved areas in each conservation category to the total area of that category). Of the metrics developed to date for measuring the importance of a given location in a connectivity network, the PC index, which is based on habitat availability, interpatch dispersal probabilities, and graph theory, performs best in practical landscape analysis (Saura and Pascual-Hortal 2007). The PC index reflects the probability that two animals randomly placed within the landscape fall into habitat areas that are reachable from each other (interconnected) given the set of habitat patches and the connections among them (Saura and Rubio 2010).

In this research, the latest shapefiles of Iran's conservation network including National Parks, Protected Areas, Wildlife Refuges, and No-Hunting Areas were overlaid with the binary presence/absence maps of the SDM analysis to calculate the extent of suitable areas within and outside the CA boundaries. The PC index was then used to prioritize CAs with the highest potential for maintaining ecological integrity and long-term population viability of the species. We assumed that each of the CAs functioned as habitat patches and used the extent of suitable habitats within them as patch attributes for calculating PC index values. PC was calculated using Conefor 2.6 software (Saura and Torne 2009). The Conefor also requires specification of distance-probability values corresponding to the dispersal ability of the target species. Given the measured dispersal distances of the species in previous studies (Farhadinia et al. 2018b), we chose $50 \mathrm{~km}$ as a median dispersal distance and $200 \mathrm{~km}$ as a maximum dispersal distance. Accordingly, as recommended by Saura and Torne (2009), we set distance-probability values of 0.5 and 0.05 for median and maximum dispersal distances, respectively. For more details on the calculation of PC index please see the Supporting Information. 
To provide more insights into the importance of CAs for habitat connectivity we also

233

234

235

236

237

238

239

\section{Results}

241 All models showed high degrees of discrimination capacity (AUC $>0.85$ and $>0.90$ for Persian

242 leopard and Asiatic cheetah, respectively) and classification accuracy (TSS $>0.58$ and $>0.68$ for

243 Persian leopard and Asiatic cheetah, respectively). For both species, GBM obtained the highest

244 AUC and TSS values. Figure 1 represents the predicted suitable habitats of the species based on

245 an ensemble of the 4 SDMs. The conversion of continuous habitat suitability models to binary

246 presence/absence maps and the application of the two qualification criteria resulted in patches of

247 suitable habitat (Fig. 1b and 1d) with a total area of $316,984 \mathrm{~km}^{2}$ and 97,338 $\mathrm{km}^{2}$ for Persian

248 leopard and Asiatic cheetah, respectively. We also found a greater mean patch size for Asiatic

249 cheetah $\left(4,424 \mathrm{~km}^{2}, 388-21,403 \mathrm{~km}^{2}\right)$ compared to Persian leopard $\left(3,522 \mathrm{~km}^{2}, 257-110,348\right.$

$250 \mathrm{~km}^{2}$ ). Merging suitable patches indicated 400,071 $\mathrm{km}^{2}$ of the region as the most suitable areas for

251 the occurrence of both of these two large carnivores (Online Appendix Fig. S3).

252

253
Gap analysis showed that the set of patches suitable for both species had intersected with 261 conservation units of the $376 \mathrm{CAs}$, which collectively cover $126,745 \mathrm{~km}^{2}(31.6 \%)$ of the total 
254 jointly suitable habitat for both species (Table 2). Among these 261 CAs, Protected Areas with a 255 total number of 117 and a total area of $53,791 \mathrm{~km}^{2}$ (13.4\% of whole suitable habitats) showed the 256 highest species representation, followed by NHAs (total number 102 and conservation coverage $\left.25733,763 \mathrm{~km}^{2}, 8.4 \%\right)$. WRs and NPs, with a total number of 23 and 19, and the total area of 30,344 $258 \mathrm{~km}^{2}(7.6 \%)$ and $8,845 \mathrm{~km}^{2}(2.5 \%)$, respectively, had the lowest species representation (Table 2).

259 Regarding the spatial configuration of the conservation units, NHAs in total showed higher 260 values of the PC index compared to the other conservation categories, although we found a high 261 variability in the dPC of the conservation units, particularly for WRs (Table 3 and Fig. 2). We 262 found that while WRs showed higher species representation (mean $=462 \mathrm{~km}^{2}, \mathrm{SD}=360 \mathrm{~km}^{2}$ ) 263 compared to NHAs (mean $\left.=337 \mathrm{~km}^{2}, \mathrm{SD}=273 \mathrm{~km}^{2}\right)$, NPs $\left(\right.$ mean $=346 \mathrm{~km}^{2}, \mathrm{SD}=334 \mathrm{~km}^{2}$ ), and 264 PAs $\left(\right.$ mean $\left.=363 \mathrm{~km}^{2}, \mathrm{SD}=330 \mathrm{~km}^{2}\right)$, NHAs surprisingly displayed the highest dPC value (mean $265=0.75, \mathrm{SD}=0.67)$, followed by WRs $($ mean $=0.73, \mathrm{SD}=0.82), \mathrm{NPs}($ mean $=0.61, \mathrm{SD}=0.63)$ 266 and PAs (mean $=0.53, \mathrm{SD}=0.65)$. In a similar pattern, comparing the contribution of CAs given 267 the three fractions of the dPC index showed that WRs had the highest score for dPCflux, while 268 NHAs had the highest values for dPCconnector (Table 3). It is worth mentioning that we found 269 this pattern regardless of the outlier values (i.e., units with $\mathrm{dPC}$ values that were extreme based on 270 a normal distribution of all conservation units). Our results also revealed that NPs and WRs had 271 the strongest relationship between conservation coverage and $\mathrm{dPC}$ index $\left(a d j . R^{2}=0.77\right.$ and 0.63 , 272 respectively), and NHAs (adj. $\left.R^{2}=0.43\right)$ with the weakest relationship (Fig. 3). 


\section{Discussion}

275 The goal of this study was to provide a more effective and comprehensive analysis of the gaps in

276 the conservation area network by taking into account both representativeness and spatial

277 connection of the CAs. While conservation coverage is widely discussed in the literature, there

278 remains a substantial lack of methods and evidence regarding how the spatial configuration of

279 conservation units influences the effectiveness of integrated networks of CAs.

Our research revealed three levels of bias in Iran's conservation network, all of which are

281 also apparent on a global scale. In the first level, and similar to the findings of Joppa and Pfaff

282 (2009), varying conservation effort has been invested in different components of the conservation

283 network (more strictly protected areas, such as National Parks and Wildlife Refuges, versus less

284 strictly conservation areas, such as Protected Areas and No-Hunting Areas), which has resulted in

285 natural habitats being granted different levels of protection (we call this conservation bias). Four

286 categories of CAs, including National Parks, Natural Heritage Sites, Wildlife Refuges and

287 Protected Areas, have been established in Iran. Although different types of CAs are established to

288 address different conservation targets and land use policies (Pressey et al. 2007), due to the higher

289 costs of protection in Categories I and II, the global growth in gazetted CAs has frequently been

290 concentrated in categories III-VI (Joppa and Pfaff 2009). As in the case of Iran, although NPs

291 demonstrate higher protection efficiency (77\%), they comprise only $7 \%$ of the total number of

292 CAs and provide the least protection coverage $(2.5 \%)$.

The CBD in general, and the flexibility of Aichi targets in particular, allow nations to design

294 their own conservation ambitions and designations to reflect local opportunities and needs.

295 Similarly, in Iran No-Hunting Areas, which are the newest category of CAs, have recently been

296 designated to restore wildlife in areas where their populations have declined due to uncontrolled 
297 hunting. NHAs have the main objective of empowering anti-poaching measures, unlike NPs or 298 WRs/PAs, where development and land use should be omitted or controlled, respectively. 299 Although more strictly protected areas have stronger legal guarantees against anthropogenic 300 impacts, conflicts with the desires of local communities often lead politicians to respond negatively 301 toward expansion or assignment of new CAs (Andam et al. 2013; Joppa and Pfaff 2009). 302 Interestingly, more strictly protected areas are not necessarily more protective of biodiversity (for 303 example see Andam et al. 2013; Ferraro et al. 2013). In this context, assigning less strictly 304 protected areas (e.g., NHAs in Iran, or IUCN's Category V and Category VI) in areas with long305 term human land-use and resource-utilization histories could be a pragmatic solution for the 306 recovery of vanishing species while affording fewer costs for conservation agencies.

Second, the establishment of CAs is concentrated in geographically remote and less 308 demanding landscapes, which we call location bias, was seen for Asiatic cheetahs. In contrast, 309 suitable habitats for the Persian leopard included higher levels of human activities, which is 310 explainable, in part, by the leopard's greater ability to coexist in human-dominated landscapes 311 (Farhadinia et al. 2018b; Soofi et al. 2018).

Finally, in addition to the conservation bias and location bias which have been convincingly 313 addressed in the literature (Joppa and Pfaff 2009; Venter et al. 2018; Watson et al. 2014), we 314 introduce 'network bias' as a new level of bias in conservation planning, where CAs are established 315 and/or expanded regardless of their position within the compositional structure of all conservation 316 units. We found that, based on a typical gap analysis (i.e., species representation), NHAs show 317 similar protection performance (conservation coverage) compared to the other CAs. However, 318 when spatial effectiveness is included in our evaluation by adding the concept of spatial 
319

320

321

322

323

324

325

326

327

328

329

330

331

332

333

334

335

336

337

338

339

340

341

configuration, NHAs are revealed to be higher priorities for habitat connectivity and population integrity.

A potential criticism of metrics used to quantify landscape connectivity is that they tend to give high importance to large patches, and undervalue the contribution of connecting elements and/or stepping stone patches (Ferrari et al. 2007). One advantage of the PC index is that it enables quantification of how different critical patches are regarding both their habitat availability and topological position in the landscape (Saura and Rubio 2010). In the approach to gap analysis, we used this advantage of PC index and regressed the probability of connectivity onto habitat availability to identify how the different types of conservation networks vary for species representation and landscape configuration (see Table 3 and Fig. 3). The highest and the lowest relationship was found for NPs and NHAs, respectively. This pattern, which is also supported by results of dPC fractions (Table 3), reflects the fact that area and habitat suitability per unit contribute to the high scores given to NPs by the dPC index, while the high scores given to NHAs by the dPCconnector reflect their greater contribuition to network connectivity compared to the other conservation units. Consequently, our gap analysis reveals that the more strictly protected areas (i.e., NPs and WRs) display high protection performance regarding species representation, while the newly-introduced and less strictly protected areas (i.e., NHAs) are stepping stones providing critical connections across the CA network. Consistent with our results, (Khosravi et al. 2018) also emphasized the importance of NHAs as stepping stones for large carnivore habitat connectivity in the deserts of central Iran.

We used the probability of connectivity index to measure the landscape integrity of the CAs. Intrinsically, the PC index measures functional connectivity of the habitat patches through the landscape (Saura and Pascual-Hortal 2007) and has been widely applied to problems of landscape 
342 conservation prioritization (Ahmadi et al. 2017; Visconti and Elkin 2009). It is worth mentioning 343 that connectivity varies depending on the attributes of the target species or communities (Baguette 344 et al. 2013). Accordingly, analyzing landscape connectivity is a species-specific process as it 345 depends on the dispersal distance and behavioral response of the target species (e.g. Baguette et 346 al. 2013; Cushman et al. 2012). While large carnivores with broad spatial requirements require 347 comprehensive and large-scale management strategies, for movement-restricted species 348 management activities could be downscaled to fine-scale structures such as hedgerow networks 349 (Dondina et al. 2018). Nevertheless, addressing connectivity in conservation design requires 350 assessing the complementarity of the components of a system to ensure the robustness of 351 ecological functions. Landscape-scale approaches can account for the complexity of ecological 352 functions, and so can enhance the capacity to designate elements of CA networks to best deliver 353 desired conservation outcomes (Cushman 2006). Here we focused on conservation planning of the 354 CAs within a large-scale management perspective and utilized the concept of focal species (e.g., 355 dominant flagship and/or umbrella species) which may provide surrogates for a wide variety of 356 subdominant species (Macdonald et al. 2017), which in turn rationalizes the use of the PC index 357 for regional multi-species conservation planning. Notwithstanding, it is germane to consider that 358 this line of reasoning suggests more research and necessitates consideration of the results of studies 359 for a wide range of species.

Based on our suitability maps, Persian leopards mainly occur in mountainous landscapes, 361 whereas Asiatic cheetahs are predominantly found in arid lowland landscapes. The species 362 distribution models we produced in this study correspond well with findings of previous researches 363 (Ahmadi et al. 2017; Farhadinia et al. 2015; Gavashelishvili and Lukarevskiy 2008; Khosravi et 364 al. 2019), in particular, preference of these species for rugged landscapes with high availability of 
365 prey species and the avoidance of human-dominated areas (see the response curve of the variables

366 provided in Online Appendix Fig. S1 and Fig. S2). However, the two species showed different

367 patterns of habitat selection in relation to human pressure. Although Asiatic cheetahs avoid areas

368 even with minor human presence, Persian leopards have moderate tolerance towards humans in

369 their habitat. Accordingly, conflict with communities due to livestock depredation is more widely

370 reported for Persian leopards than Asiatic cheetahs (Babrgir et al. 2017; Soofi et al. 2018).

\section{Conclusions}

372 Expansion of current CAs and designating new conservation-oriented areas has been emphasized

373 as an important strategy to mitigate the impacts of human society on biodiversity (COP 2010). Due

374 to the shortage of funding resources and staff, as well as external threats from human land use

375 changes (Hearn et al. 2018; Joppa and Pfaff 2009), efforts to assess the effectiveness of CAs and

376 to strategically allocate management activities would greatly benefit from an assessment of the

377 collective effectiveness of the entire network of CAs (Le Saout et al. 2013). In this research, the

378 network of CAs of Iran was considered as a model for our new approach to gap analysis. This

379 approach evaluates the different categories of CAs given their level of protection, species

380 representation, and network connectivity. We showed that this approach is a simple and efficient

381 method for rapid assessment of completeness and effectiveness of CA networks. Although species

382 representation is widely used, we showed that taking into account both representativeness and 383 spatial configuration of the CAs can effectively enhance conservation planning and can help 384 address three main biases, particularly the network bias. The wide range of conservation area 385 categories on a global scale, as well as the necessity to consider these three aspects in any gap 386 analysis, suggests that our approach may be useful as a global model applicable to other species 387 and geographical contexts. 
Acknowledgments We are grateful for the financial and technical support of the DoE of Iran, the Global Environmental Facilities (GEF), the United Nations Development Program (UNDP), and the Wildlife Conservation Society (WCS). We thank K. Baradarani and A. Taktehrani for their help in collecting leopard occurrence data. Our special thanks go to the game guards of the DoE who helped us in field sampling. MA received a sabbatical research fund from the Ministry of Sciences, Research and Technology of Iran for a 6-month research in Swiss Federal Research Institute (WSL). MSF was supported by a research fellowship from Oxford Martin School at the University of Oxford.

\section{References}

Ahmadi M, Nezami Balouchi B, Jowkar H, Hemami MR, Fadakar D, Malakouti-Khah S, Ostrowski S (2017) Combining landscape suitability and habitat connectivity to conserve the last surviving population of cheetah in Asia. Diversity and Distributions 23:592-603. https://doi.org/10.1111/ddi.12560

Andam KS, Ferraro PJ, Hanauer MM (2013) The effects of protected area systems on ecosystem restoration: a quasi- experimental design to estimate the impact of Costa Rica's protected area system on forest regrowth. Conservation Letters 6:317-323

Araújo MB, Lobo JM, Moreno JC (2007) The effectiveness of Iberian protected areas in conserving terrestrial biodiversity. Conservation Biology 21:1423-1432. https://doi.org/10.1111/j.15231739.2007.00827.x

Ashrafzadeh MR, Khosravi R, Ahmadi M, Kaboli M (2018) Landscape heterogeneity and ecological niche isolation shape the distribution of spatial genetic variation in Iranian brown bears, Ursus arctos (Carnivora: Ursidae). Mammalian Biology 93:64-75

Babrgir S, Farhadinia MS, Moqanaki EM (2017) Socio-economic consequences of cattle predation by the Endangered Persian leopard Panthera pardus saxicolor in a Caucasian conflict hotspot, northern Iran. Oryx 51:124-130

Baguette M, Blanchet S, Legrand D, Stevens VM, Turlure C (2013) Individual dispersal, landscape connectivity and ecological networks. Biological Reviews 88:310-326

Carroll C, Noss RF, Paquet PC (2001) Carnivores as focal species for conservation planning in the Rocky Mountain region. Ecological applications 11:961-980

CBD (2010) The Strategic Plan for Biodiversity 2011-2020 and the Aichi Biodiversity Targets, Nagoya, Japan, 18 to 29 October 2010.

COP C (2010) Decision X/2: Strategic Plan for Biodiversity 2011-2020. Convention on Biological Diversity, Nagoya, Japan. 
Cushman SA (2006) Effects of habitat loss and fragmentation on amphibians: a review and prospectus. Biological Conservation 128:231-240

Cushman SA et al. (2018) Prioritizing core areas, corridors and conflict hotspots for lion conservation in southern Africa. PloS one 13:e0196213

Cushman SA, Landguth EL, Flather CH (2012) Evaluating the sufficiency of protected lands for maintaining wildlife population connectivity in the US northern Rocky Mountains. Diversity and Distributions 18:873-884

Cushman SA, Macdonald EA, Landguth EL, Malhi Y, Macdonald DW (2017) Multiple-scale prediction of forest loss risk across Borneo. Landscape ecology 32:1581-1598

Dondina O, Saura S, Bani L, Mateo-Sánchez MC (2018) Enhancing connectivity in agroecosystems: focus on the best existing corridors or on new pathways? Landscape Ecology 33:1741-1756

Dormann CF et al. (2007) Methods to account for spatial autocorrelation in the analysis of species distributional data: a review. Ecography 30:609-628

Farhadinia M, Hemami M-R (2010) Prey selection by the critically endangered Asiatic cheetah in central Iran. Journal of Natural History 44:1239-1249

Farhadinia MS, Ahmadi M, Sharbafi E, Khosravi S, Alinezhad H, Macdonald DW (2015) Leveraging transboundary conservation partnerships: persistence of Persian leopard (Panthera pardus saxicolor) in the Iranian Caucasus. Biological Conservation 191:770-778

Farhadinia MS et al. (2016) Wandering the barren deserts of Iran: illuminating high mobility of the Asiatic cheetah with sparse data. Journal of Arid Environments 134:145-149

Farhadinia MS et al. (2017) The critically endangered Asiatic cheetah Acinonyx jubatus venaticus in Iran: a review of recent distribution, and conservation status. Biodiversity and Conservation 26:10271046

Farhadinia MS, Johnson PJ, Hunter LT, Macdonald DW (2018a) Persian leopard predation patterns and kill rates in the Iran-Turkmenistan borderland. Journal of Mammalogy 99:713-723

Farhadinia MS, Johnson PJ, Macdonald DW, Hunter LT (2018b) Anchoring and adjusting amidst humans: Ranging behavior of Persian leopards along the Iran-Turkmenistan borderland. PLoS ONE 13:e0196602

Ferrari JR, Lookingbill TR, Neel MC (2007) Two measures of landscape-graph connectivity: assessment across gradients in area and configuration. Landscape ecology 22:1315-1323

Ferraro PJ, Hanauer MM, Miteva DA, Canavire-Bacarreza GJ, Pattanayak SK, Sims KR (2013) More strictly protected areas are not necessarily more protective: evidence from Bolivia, Costa Rica, Indonesia, and Thailand. Environmental Research Letters 8:025011

Franklin J (2010) Mapping species distributions: spatial inference and prediction. Cambridge University Press,

Gaston KJ, Jackson SF, Cantú-Salazar L, Cruz-Piñón G (2008) The ecological performance of protected areas. Annual review of ecology, evolution, and systematics 39:93-113

Gavashelishvili A, Lukarevskiy V (2008) Modelling the habitat requirements of leopard Panthera pardus in west and central Asia. Journal of Applied Ecology 45:579-588

Ghoddousi A, Hamidi AK, Ghadirian T, Ashayeri D, Khorozyan I (2010) The status of the endangered Persian leopard Panthera pardus saxicolor in Bamu National Park, Iran. Oryx 44:551-557

Guisan A et al. (2013) Predicting species distributions for conservation decisions. Ecology letters 16:14241435

Hearn AJ et al. (2018) Evaluating scenarios of landscape change for Sunda clouded leopard connectivity in a human dominated landscape. Biological Conservation 222:232-240

Hemami M-R, Esmaeili S, Brito JC, Ahmadi M, Omidi M, Martínez-Freiría F (2018) Using ecological models to explore niche partitioning within a guild of desert felids. Hystrix, the Italian Journal of Mammalogy 29:216-222

Jenkins CN, Pimm SL, Joppa LN (2013) Global patterns of terrestrial vertebrate diversity and conservation. Proceedings of the National Academy of Sciences 110:E2602-E2610 
Jenkins CN, Van Houtan KS, Pimm SL, Sexton JO (2015) US protected lands mismatch biodiversity priorities. Proceedings of the National Academy of Sciences 112:5081-5086

Jennings MD (2000) Gap analysis: concepts, methods, and recent results. Landscape ecology 15:5-20

Joppa LN, Pfaff A (2009) High and far: biases in the location of protected areas. PloS one 4:e8273

Juffe-Bignoli D et al. (2014) Protected planet report 2014. UNEP-WCMC: Cambridge, UK 11

Karami M, Ghadirian T, Faizolahi K (2012) The atlas of mammals of Iran. Department of Environment. Tehran, Iran,

Khosravi R, Hemami M-R (2019) Identifying landscape species for ecological planning. Ecological indicators 99:140-148

Khosravi R, Hemami M-R, Cushman SA (2019) Multi-scale niche modeling of three sympatric felids of conservation importance in central Iran. Landscape Ecology 34:2451-2467

Khosravi R, Hemami MR, Cushman SA (2018) Multispecies assessment of core areas and connectivity of desert carnivores in central Iran. Diversity and Distributions 24:193-207

Kiabi BH, Dareshouri BF, Ghaemi RA, Jahanshahi M (2002) Population status of the Persian leopard (Panthera pardus saxicolor Pocock, 1927) in Iran. Zoology in the Middle East 26:41-47

Kolahi M, Sakai T, Moriya K, Makhdoum MF (2012) Challenges to the future development of Iran's protected areas system. Environmental management 50:750-765

Kramer-Schadt S et al. (2013) The importance of correcting for sampling bias in MaxEnt species distribution models. Diversity and Distributions 19:1366-1379. http://dx.doi.org/10.1111/ddi.12096

Le Saout $\mathrm{S}$ et al. (2013) Protected areas and effective biodiversity conservation. Science 342:803-805

Macdonald DW et al. (2018) Multi-scale habitat selection modeling identifies threats and conservation opportunities for the Sunda clouded leopard (Neofelis diardi). Biological Conservation 227:92-103

Macdonald E et al. (2017) Identifying ambassador species for conservation marketing. Global ecology and conservation 12:204-214

Maiorano L, Falcucci A, Boitani L (2006) Gap analysis of terrestrial vertebrates in Italy: priorities for conservation planning in a human dominated landscape. Biological Conservation 133:455-473

Meyer SR, Beard K, Cronan CS, Lilieholm RJ (2015) An analysis of spatio-temporal landscape patterns for protected areas in northern New England: 1900-2010. Landscape ecology 30:1291-1305

Pressey RL, Cabeza M, Watts ME, Cowling RM, Wilson KA (2007) Conservation planning in a changing world. Trends in Ecology \& Evolution 22:583-592. http://www.sciencedirect.com/science/article/pii/S0169534707002807

R Development Core Team (2016) R: A language and environment for statistical computing. R Foundation for Statistical Computing, Vienna, Austria.

Rodrigues AS et al. (2004a) Global gap analysis: priority regions for expanding the global protected-area network. BioScience 54:1092-1100

Rodrigues AS et al. (2004b) Effectiveness of the global protected area network in representing species diversity. Nature 428:640

Sanderson EW, Jaiteh M, Levy MA, Redford KH, Wannebo AV, Woolmer G (2002) The human footprint and the last of the wild: the human footprint is a global map of human influence on the land surface, which suggests that human beings are stewards of nature, whether we like it or not. AIBS Bulletin 52:891-904

Santini L, Di Marco M, Boitani L, Maiorano L, Rondinini C (2014) Incorporating spatial population structure in gap analysis reveals inequitable assessments of species protection. Diversity and distributions 20:698-707

Santini L, Saura S, Rondinini C (2016) Connectivity of the global network of protected areas. Diversity and Distributions 22:199-211

Saura S, Bertzky B, Bastin L, Battistella L, Mandrici A, Dubois G (2018) Protected area connectivity: Shortfalls in global targets and country-level priorities. Biological conservation 219:53-67 
Saura S, Pascual-Hortal L (2007) A new habitat availability index to integrate connectivity in landscape conservation planning: comparison with existing indices and application to a case study. Landscape and Urban Planning 83:91-103

Saura S, Rubio L (2010) A common currency for the different ways in which patches and links can contribute to habitat availability and connectivity in the landscape. Ecography 33:523-537

Saura S, Torne J (2009) Conefor Sensinode 2.2: a software package for quantifying the importance of habitat patches for landscape connectivity. Environmental Modelling \& Software 24:135-139

Soofi M et al. (2018) Assessing the relationship between illegal hunting of ungulates, wild prey occurrence and livestock depredation rate by large carnivores. Journal of Applied Ecology 56:365-374. https://besjournals.onlinelibrary.wiley.com/doi/abs/10.1111/1365-2664.13266

Thuiller W, Lafourcade B, Engler R, Araújo MB (2009) BIOMOD-a platform for ensemble forecasting of species distributions. Ecography 32:369-373

Venter O, Magrach A, Outram N, Klein CJ, Possingham HP, Di Marco M, Watson JE (2018) Bias in protected- area location and its effects on long- term aspirations of biodiversity conventions. Conservation biology 32:127-134

Visconti P et al. (2019) Protected area targets post-2020. Science 364:239-241

Visconti P, Elkin C (2009) Using connectivity metrics in conservation planning-When does habitat quality matter? Diversity and Distributions 15:602-612

Watson JEM, Dudley N, Segan DB, Hockings M (2014) The performance and potential of protected areas. Nature 515:67. http://dx.doi.org/10.1038/nature13947

Yousefi M, Ahmadi M, Nourani E, Behrooz R, Rajabizadeh M, Geniez P, Kaboli M (2015) Upward Altitudinal Shifts in Habitat Suitability of Mountain Vipers since the Last Glacial Maximum. PloS one 10:e138087 
Table legend:

Table 1. The number of presence points collected to be used in SDM.

\begin{tabular}{lccc}
\hline & Total observations & Direct field sampling & Camera traps \\
\hline Persian leopard & 632 & 498 & 134 \\
Asiatic cheetah & 680 & 485 & 195 \\
\hline
\end{tabular}

Table 2. Total area and proportion of protection granted to the suitable habitats by Iran's conservation network with respect to their corresponding IUCN categories. Conservation coverage: ratio of conserved habitats to the total suitable habitats. Conservation efficiency: ratio of conserved habitats to the total area of each conservation unit.

\begin{tabular}{lcccccc}
\hline Iran CAs & IUCN Category & Number & $\begin{array}{c}\text { Area } \\
\left.\mathbf{( k m}^{2}\right)\end{array}$ & $\begin{array}{c}\text { Conservation } \\
\text { coverage }\left(\mathbf{k m}^{\mathbf{2}}\right)\end{array}$ & $\begin{array}{c}\text { Conservation } \\
\text { coverage (\%) }\end{array}$ & $\begin{array}{c}\text { Conservation } \\
\text { efficiency }(\%)\end{array}$ \\
\hline National Park & Category II & 19 & 11426 & 8845 & 2.5 & 77.4 \\
Wildlife Refuge & Category IV & 23 & 49480 & 30344 & 7.6 & 61.3 \\
Protected Area & Category IV-VI & 117 & 77104 & 53791 & 13.4 & 69.8 \\
No-hunting Area & Category V & 102 & 54047 & 33763 & 8.4 & 62.4 \\
\hline Total & & 261 & 192059 & 126745 & 31.6 & 65.9 \\
\hline
\end{tabular}

Iran's conservation network are those with an intersection with suitable habitat patches

Table 3. Mean values of dPC index and its three fractions (intra, flux and connector) calculated for different categories of conservation areas. NPs: National Parks, WRs: Wildlife Refuges, PAs: Protected Area, NHAs: No-hunting Area.

\begin{tabular}{|c|c|c|c|c|c|c|c|c|}
\hline & \multicolumn{2}{|c|}{$\mathrm{dPC}$} & \multicolumn{2}{|c|}{ dPCintra } & \multicolumn{2}{|c|}{ dPCflux } & \multicolumn{2}{|c|}{ dPCconnector } \\
\hline & $50-\mathrm{km}$ & 200-km & $50-\mathrm{km}$ & 200-km & $50-\mathrm{km}$ & $200-\mathrm{km}$ & $50-\mathrm{km}$ & 200-km \\
\hline NPs & 0.61 & 0.63 & 0.02 & 0.01 & 0.45 & 0.49 & 0.14 & 0.13 \\
\hline WRs & 0.73 & 0.74 & 0.02 & 0.02 & 0.52 & 0.54 & 0.19 & 0.18 \\
\hline PAs & 0.53 & 0.58 & 0.01 & 0.06 & 0.42 & 0.41 & 0.10 & 0.11 \\
\hline NHAs & 0.75 & 0.73 & 0.01 & 0.03 & 0.46 & 0.43 & 0.28 & 0.27 \\
\hline
\end{tabular}




\section{Figure Legends:}

Fig. 1 Habitat suitability of Persian leopard (a, b) and Asiatic cheetah (c, d) in southwestern Asia. Continuous maps (a, c) were derived based on an ensemble distribution model of GLM, GAM, GBM and MaxEnt models. Binary maps (b, d) generated to identify core habitat patches using 10-percentile suitability at occurrence points of each species as a presence/absence threshold

Fig. 2 Scatterplot of species representation (suitability coverage) and the probability of connectivity index (dPC) of the No-hunting Areas (NHAs), National Parks (NPs), Protected Areas (PAs) and Wildlife Refuges (WRs). dPC scores were calculated based on a median (50km) and maximum dispersal distance $(200 \mathrm{~km})$ of the species

Fig. 3 Nonlinear regression between species representation (suitability coverage) and the probability of connectivity index (dPC) of Iranian conservation units. dPC scores were calculated based on a median $(50 \mathrm{~km})$ and maximum dispersal distance $(200 \mathrm{~km})$ of the species. NHAs: NoHunting Areas, NPs: National Parks, PAs: Protected Areas, WRs: Wildlife Refuges 


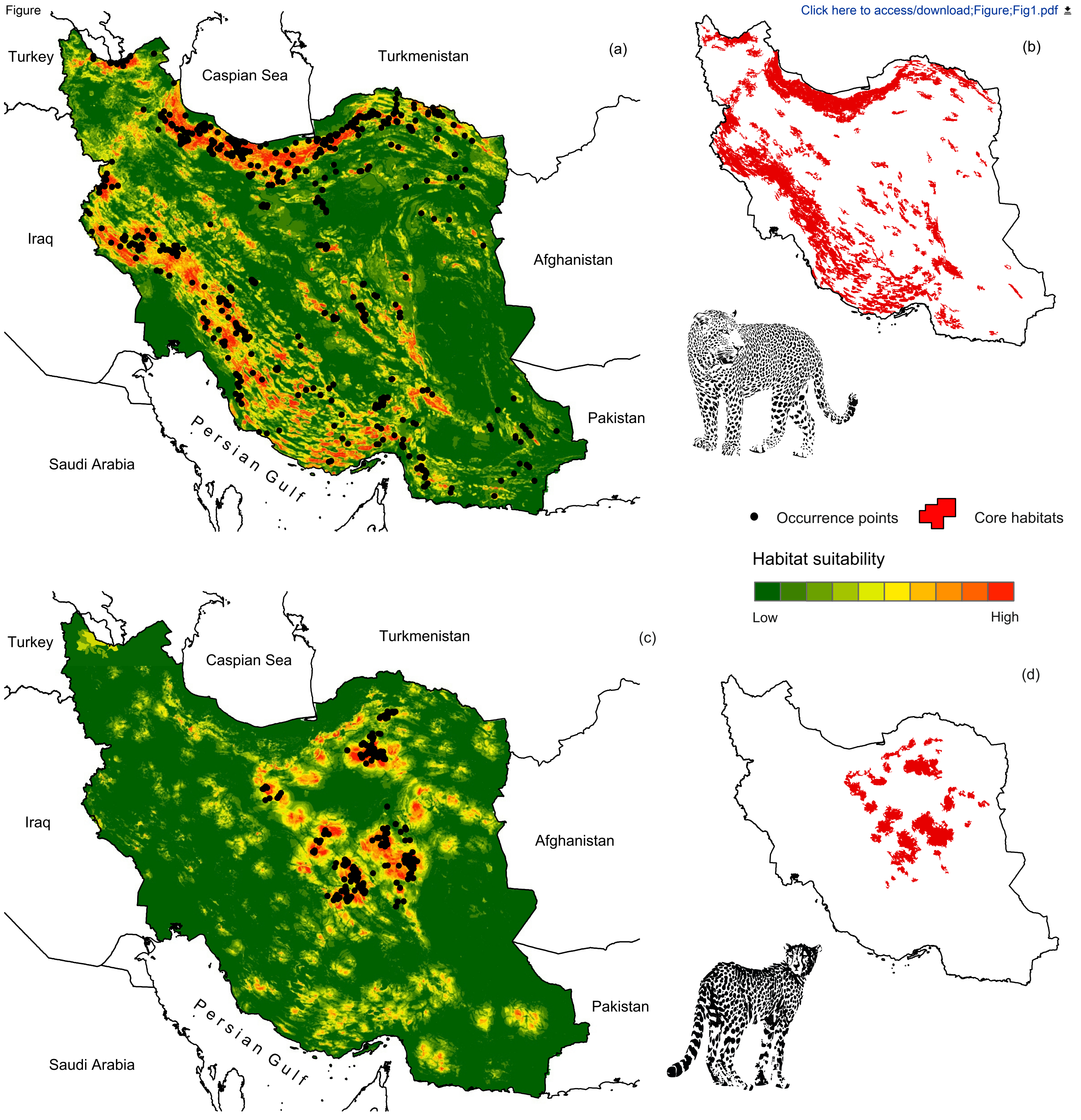


Click here thactesshtowntoad;Figure;Fig2.pdf $\underline{ \pm}$
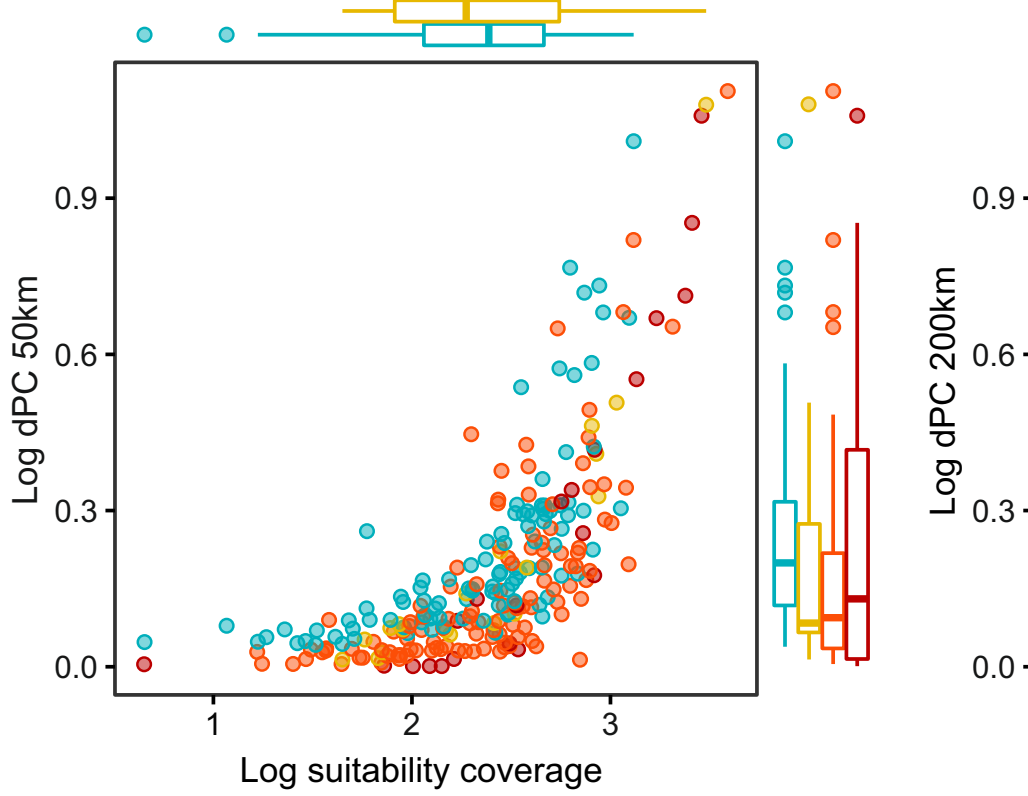

O

0

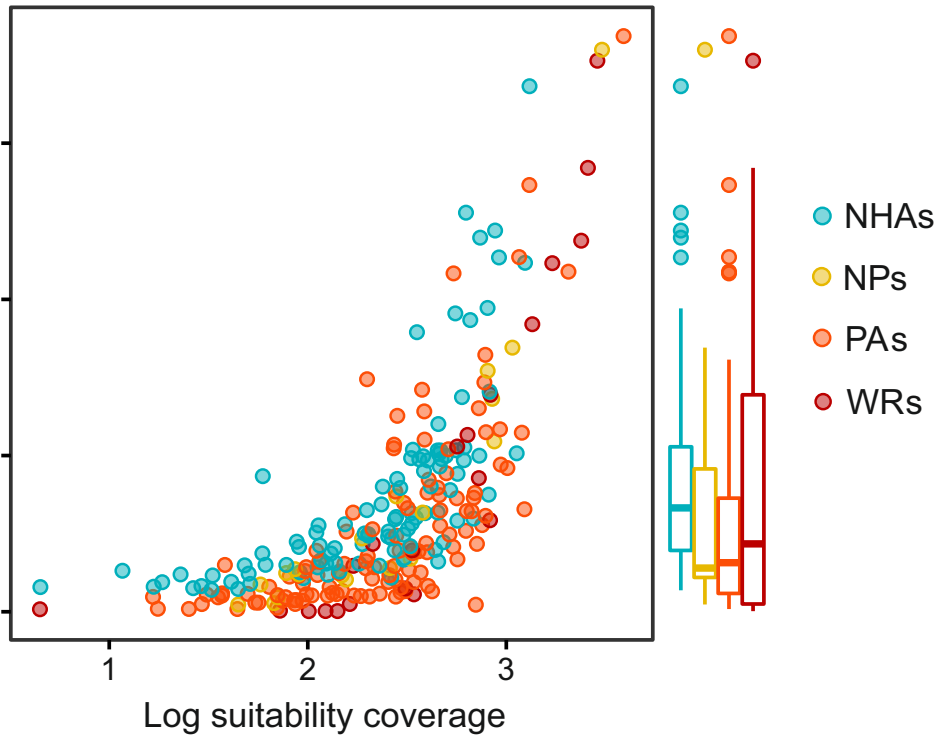


